\title{
Efficiency estimation of the shaped hot rolled steel product mix of India and Ukraine
}

\author{
Victor Gaidaichuk¹, Dmytro Bannikov², Anatoly Radkevych ${ }^{3}$, Antonina Muntian ${ }^{4}$ \\ ${ }^{1}$ Kyiv National University of Construction and Architecture \\ Kyiv Povitroflotsky avenu, 31, Kyiv 03680, Ukraine \\ ${ }^{2}$ Dnipro after V. National University of Rail Transport Lazaryan \\ Dnipro 2, Lazaryana, St., Dnipro 49010, Ukraine \\ 11viktor gaydaychuk@bigmir.net, orcid.org/0000-0003-2059-7433 \\ 2bdo2020@yahoo.com, orcid.org/0000-0002-9019-9679 \\ 3anatolij.radkevich@gmail.com, orcid.org/0000-0001-6325-8517 \\ 르untonya@gmail.com, orcid.org/ 0000-0001-8375-4067
}

DOI: $10.32347 / 2522-4182.4 .2019 .4-9$

Introduction. Hot-rolled steel shaped sections form the basis for the design of structural elements, because they not only provide a high level of manufacturability, but also the necessary reliability and quality of constructions. Therefore, the question of the construction and efficiency of product mix of such sections remains quite relevant, because in the metal structures market there are constantly certain economic events that lead to a change in demand for different types of steel shaped sections.

The expansion of cooperation between countries, which has been constantly occurring in the world over the last decades, among others in the field of metalwork design, creates the conditions for a kind of interchangeability of steel sections in the civil structures projects performed by design bureaus in different parts of the globe. One of the decisive factors in this case is the possibility of using national varieties of rolled steel product mix of different countries.

This is the exact situation that is more and more often getting the matter under the conditions of collaboration between specialists of India and Ukraine in the field of design and construction of mini-factories for the pharmacological industry. Such small businesses are able to produce large volumes of relatively cheap medicines under licenses of well-known brands. However, buildings and territories that are now often used in India and Ukraine to house such industries have been unused and unattended for some time. During their reconstruction, appropriate project proposals are developed, which in their term aim to use local materials, facilities and manpower. In this connection, there is a question of comparison and possible replacement of shaped rolled steel, which is quite widely used in such cases.

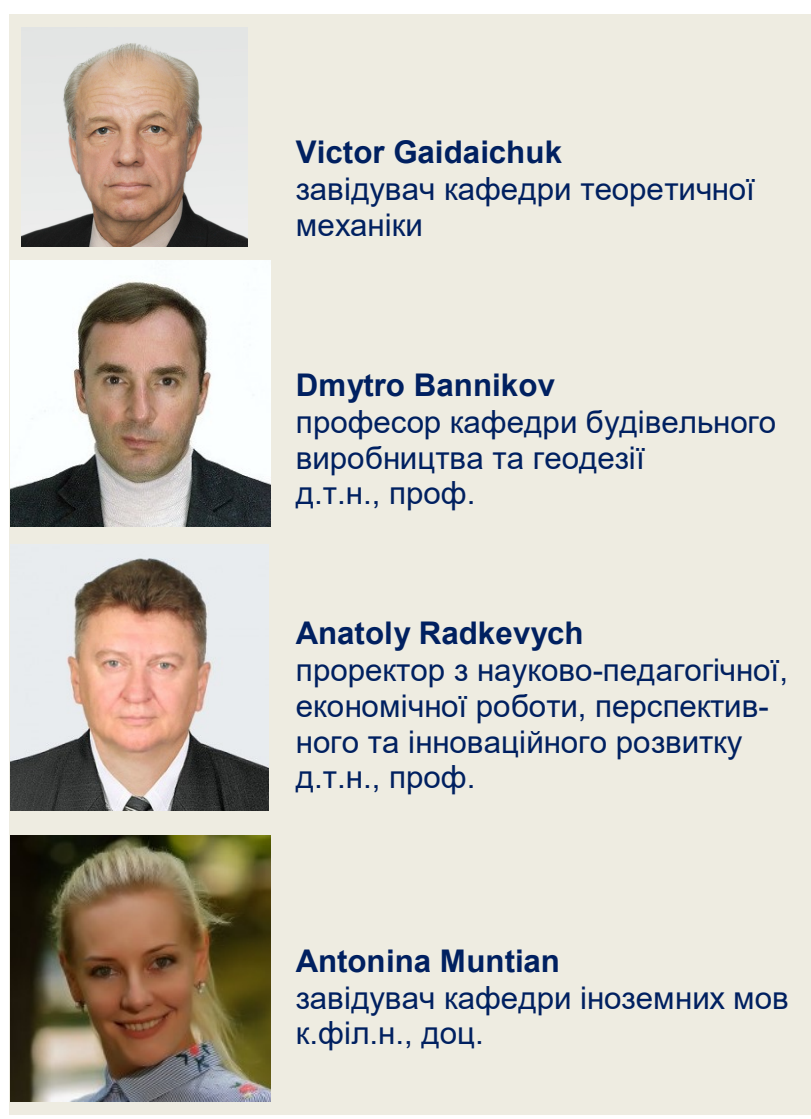

The main purpose of this publication is to present a comparative study of the effectiveness and analysis of the peculiarities of use of the shaped rolled metal products of India in comparison with the current similar domestic product mix of Ukraine.

General organization of product mix. Unlike Ukraine, India's main hot-rolled shaped sections are compiled in a single national standard - IS 808 [1]. It provides for only four types of sections - equal leg and unequal leg 
angle, channel and flanged beams. Compared with the domestic product mix base [2-6] there are no T-sections, which are not currently popular in Ukraine.

In general, the overall organization of the IS 808 standard [1] is similar to domestic products - all sections are grouped by types of sections and for each of them their geometrical dimensions, geometrical characteristics and mass indicators of running meter are given. The major differences are related to the mathematical notation of some of these variables. Thus, the height of the section is denoted by $\mathrm{D}$, the width and thickness of its flanges as $\mathrm{B}$ and $\mathrm{T}$ respectively, the distance to the weight centers as $\mathrm{Ci}$, and the crosssectional area as a. The corresponding designations in domestic product mix are the height $\mathrm{h}$, the width and thickness of the flanges $\mathrm{b}$ and $\mathrm{t}$, the distances to the weight centers $\mathrm{z}$, while the cross-sectional area does not have its own special designation.

Unlike domestic product mix, the IS 808 standard [1] does not provide data on the tolerances of geometric dimensions of the sections from the declared ones, and there are no recommendations regarding the length of the sections.

The main fundamental difference in the section system of India for beam and channel sections is the division of them into four varieties - junior, light, medium and heavy. Geometrically, they have the same height, but other geometric dimensions (wall and flange thicknesses and flange width) change. Due to this, it is possible in practice to design the cross section more economically, which will more accurately meet the required geometric characteristics.

Also, beam and channel sections have the section height changing pitch of $25 \mathrm{~mm}$ (up to a height of $250 \mathrm{~mm}$ ), and then $-50 \mathrm{~mm}$. In the domestic product mix base this pitch is equal to $20 \mathrm{~mm}$ (up to a height of approximately 220 $\mathrm{mm}$ ), and further $-30 \mathrm{~mm}$. That is, a sparser pitch, placed in IS 808 [1], is compensated in a peculiar way by the above-described systemdivision of sections into varieties by geometric characteristics. Accordingly, the IS 808 [1] gradation coefficient reaches 1.35 , which is higher than for domestic product mix for which the maximum value reaches only 1.20.

Angle section. In accordance with IS 808 [1], angle sections, both with equal legs and unequal legs have geometry similar to domestic standards - legs have parallel faces without bias with the same thickness. In this case, the section pitch is sparser and the thickness range is wider. Thus, for equal leg angles, there are 91 sections (maximum angle $200 \times 200 \times 25)$ versus 89 according to the national standard DSTU 2251-93 [2] (maximum angle $250 \times 250 \times 35$ ), and for unequal leg angles there are 111 sections (maximum angle $200 \times 150 \times 20$ ) against 62 according to the national standard GOST $8510-86 *$ [3] (maximum angle $200 \times 125 \times$ 16). This is due to the high prevalence of angle sections in steel structural members. In many cases, such elements are made in the form of spacious box girders for the perception of high wind and especially seismic loads in India, in accordance with standards [7, 8]. For the chords of these girders, they use unit angle sections, oriented by legs in the vertical and horizontal dimensions, and joined by a grid from section steel or flat steel. The absence of a load coupling decreasing coefficient by standard [9] will further increase the overall loading effect on the structure.

The ratio of the sides of unequal leg angles according to the IS 808 standard [1] is similar to the one adopted in domestic design practice and is on average 1:1.6. Although for sections with significant leg widths it tends to increase to $1: 2.0$

Channel section. Channel section in accordance with IS 808 [1] is applied to two types - both taper flange channel and parallel flange one.

For the first type, the flange taper is determined by the angle of inclination of the inner face of the flange, which should be 91.5 $\circ$ or $96^{\circ}$. According to the domestic product mix DSTU 3436-96 [4] the flange taper is not clearly defined and can fluctuate within $4-10$ $\%$, which corresponds to the range 92.5 - 95.5 $\circ$. The maximum section has a height of 400 $\mathrm{mm}$, as in the domestic standard DSTU 343696 [4]. Lightweight varieties have a cross- 
sectional area and, accordingly, a mass per meter, on average $30-35 \%$ smaller than domestic sections, and heavy varieties - on average $35-40 \%$ larger.

Second-class Indian standard sections are only available in two different types - medium and heavy. At the same time, heavy ones also have an area and, accordingly, a cross-section weight $35-40 \%$ larger than the sections of the domestic product mix. However, the domestic range provides two additional series economic and light, whose sections are almost twice as light as Indian ones.

The total number of taper flange channel sections of all product ranges according to IS 808 standard [1] is 40 items against 18 according to the national standard DSTU 3436-96 [4], and parallel flange ones - 20 against 43 . Their total number is almost the same -60 vs. 61 .

I-beam section. I-beam sections in IS 808 [1] have the largest number of products. All of them are provided only with a flange taper that varies between 91.5 and $98^{\circ}$. The medium beams are the closest to the national standard GOST 8239-89 [5]. Their maximum height varies up to $600 \mathrm{~mm}$, and the total number is 14 product items against 17 in the domestic product mix. Indian sections of this variety are found to be $15-20 \%$ heavier than domestic ones, with an approximate equal ratio of the flange width to the height, which is on average equal to $0.45-0.50$.

Also in the Indian product mix there is a special kind of beam - column section. It also has a flange taper different from the national standard GOST 26020-83 [6], but the flange width to height ratio is very close to 1.0 . Its maximum height is $450 \mathrm{~mm}$ against $400 \mathrm{~mm}$ according to the domestic product mix of the column series.

The total number of beam sections of all varieties according to IS 808 [1] is 79 items against 108 according to national standards GOST 8239-89 [5] and GOST 26020-83 [6] together.
From the theory of product mix it is known that the efficiency of beam sections is determined by special specific indicators, which are calculated according to the following expressions (the designations of geometric parameters are retained according to the domestic product mix):

- the specific moment of resistance

$$
\bar{W}=\frac{\sqrt{\lambda_{w}}}{4} \cdot\left(2-\frac{4}{3} \cdot k\right) \cdot \sqrt{k}
$$

- the specific moment of inertia

$\bar{I}=\frac{\lambda_{w}}{12} \cdot(3-2 \cdot k) \cdot k$

- $\quad$ the specific radius of inertia

$\bar{i}=\frac{1}{2} \cdot \sqrt{\frac{\lambda_{w} \cdot\left(3 \cdot k-2 \cdot k^{2}\right)}{3}}$

where $\lambda_{w}=\frac{h_{w}}{t_{w}}-$ beam wall flexibility;

$h_{w}$ - beam wall height;

$t_{w}$ - beam wall thickness;

$k=\frac{h_{w} \cdot t_{w}}{A}-$ conditional index of the beam wall area;

$A$ - cross-sectional square of the beam

The values of these indicators are desirable to be as high as possible, which characterizes the effectiveness of the product mix of beam sections. Tables $1-3$ give a comparison of the geometric characteristics of the beam sections according to the above standards of India and Ukraine for some of the most characteristic cross sections. Designations of geometric parameters are saved according to the domestic product mix:

$h$ - beam height,

$b$ - beam flange width;

$t_{w}$ - beam wall thickness;

$t_{f}$ - beam flange thickness;

$I$ - moment of inertia of the beam;

$W$ - moment of resistance of the beam;

$M$ - beam mass per unit length. 
Table 1 Standard

\begin{tabular}{|c|c|c|c|c|c|c|c|c|}
\hline Parameter & $\begin{array}{c}\text { IS 808 } \\
{[1]}\end{array}$ & $\begin{array}{c}\text { IS 808 } \\
{[1]}\end{array}$ & $\begin{array}{c}\text { IS 808 } \\
{[1]}\end{array}$ & $\begin{array}{c}\text { IS 808 } \\
{[1]}\end{array}$ & $\begin{array}{c}\text { GOST } \\
8239- \\
89[5]\end{array}$ & $\begin{array}{c}\text { GOST } \\
26020- \\
83[6]\end{array}$ & $\begin{array}{c}\text { GOST } \\
26020- \\
83[6]\end{array}$ & $\begin{array}{c}\text { GOST } \\
26020- \\
83[6]\end{array}$ \\
\hline Designation & LB200 & MB200 & WB200 & HB200 & 20 & $20 \mathrm{~B} 1$ & $20 \mathrm{SH} 1$ & $20 \mathrm{~K} 1$ \\
\hline$h, \mathrm{~mm}$ & 200 & 200 & 200 & 200 & 200 & 200 & 193 & 195 \\
\hline$b, \mathrm{~mm}$ & 100 & 100 & 140 & 200 & 100 & 100 & 150 & 200 \\
\hline$t_{w}, \mathrm{~mm}$ & 5.4 & 5.7 & 6.1 & 6.1 & 5.2 & 5.6 & 6.0 & 6.5 \\
\hline$t_{f, \mathrm{~mm}}$ & 7.3 & 10.0 & 9.0 & 9.0 & 8.4 & 8.5 & 9.0 & 10.0 \\
\hline$I, \mathrm{~cm}^{4}$ & 1700 & 2120 & 2620 & 3600 & 1840 & 1943 & 2660 & 3820 \\
\hline$W, \mathrm{~cm}^{3}$ & 170 & 212 & 262 & 360 & 184 & 194 & 275 & 392 \\
\hline$A, \mathrm{~cm}^{2}$ & 25.3 & 30.8 & 36.7 & 47.5 & 26.8 & 28.5 & 39.0 & 52.8 \\
\hline$M, \mathrm{~kg} / \mathrm{m}$ & 19.8 & 24.2 & 28.8 & 37.3 & 21.0 & 22.4 & 30.6 & 41.5 \\
\hline $\bar{W}$ & 1.36 & 1.26 & 1.20 & 1.11 & 1.35 & 1.30 & 1.15 & 1.03 \\
\hline $\bar{I}$ & 2.50 & 2.05 & 1.80 & 1.47 & 2.39 & 2.23 & 1.61 & 1.24 \\
\hline $\bar{i}$ & 1.58 & 1.43 & 1.34 & 1.21 & 1.55 & 1.49 & 1.27 & 1.11 \\
\hline
\end{tabular}

Table 2 Standard

\begin{tabular}{|c|c|c|c|c|c|c|c|c|}
\hline Parameter & $\begin{array}{c}\text { IS 808 } \\
{[1]}\end{array}$ & $\begin{array}{c}\text { IS 808 } \\
{[1]}\end{array}$ & $\begin{array}{c}\text { IS 808 } \\
{[1]}\end{array}$ & $\begin{array}{c}\text { IS 808 } \\
{[1]}\end{array}$ & $\begin{array}{c}\text { GOST } \\
8239- \\
89[5]\end{array}$ & $\begin{array}{c}\text { GOST } \\
26020- \\
83[6]\end{array}$ & $\begin{array}{c}\text { GOST } \\
26020- \\
83[6]\end{array}$ & $\begin{array}{c}\text { GOST } \\
\text { 26020- } \\
83]\end{array}$ \\
\hline Designation & LB300 & MB300 & WB300 & HB300 & 30 & $30 \mathrm{~B} 1$ & $30 \mathrm{SH} 1$ & $30 \mathrm{~K} 1$ \\
\hline$h, \mathrm{~mm}$ & 300 & 300 & 300 & 300 & 300 & 296 & 291 & 296 \\
\hline$b, \mathrm{~mm}$ & 150 & 140 & 200 & 250 & 135 & 140 & 200 & 300 \\
\hline$t_{w}, \mathrm{~mm}$ & 6.7 & 7.7 & 7.4 & 7.6 & 6.5 & 5.8 & 8.0 & 9.0 \\
\hline$t_{f, \mathrm{~mm}}$ & 9.4 & 13.1 & 10.0 & 10.6 & 10.2 & 8.5 & 11.0 & 13.5 \\
\hline$I, \mathrm{~cm}^{4}$ & 7330 & 8990 & 9820 & 12600 & 7080 & 6328 & 10400 & 18110 \\
\hline$W, \mathrm{~cm}^{3}$ & 489 & 600 & 655 & 840 & 472 & 427 & 715 & 1223 \\
\hline$A, \mathrm{~cm}^{2}$ & 48.1 & 58.6 & 61.3 & 74.8 & 46.5 & 41.9 & 68.3 & 108.0 \\
\hline$M, \mathrm{~kg} / \mathrm{m}$ & 37.7 & 46.0 & 48.1 & 58.8 & 36.5 & 32.9 & 53.6 & 84.8 \\
\hline $\bar{W}$ & 1.50 & 1.36 & 1.39 & 1.31 & 1.52 & 1.60 & 1.29 & 1.10 \\
\hline $\bar{I}$ & 3.04 & 2.43 & 2.48 & 2.11 & 3.11 & 3.45 & 2.09 & 1.42 \\
\hline $\bar{i}$ & 1.74 & 1.56 & 1.57 & 1.45 & 1.76 & 1.86 & 1.45 & 1.19 \\
\hline
\end{tabular}


Table 3 Standard

\begin{tabular}{|c|c|c|c|c|c|c|c|c|}
\hline Parameter & $\begin{array}{c}\text { IS 808 } \\
{[1]}\end{array}$ & $\begin{array}{c}\text { IS 808 } \\
{[1]}\end{array}$ & $\begin{array}{c}\text { IS 808 } \\
{[1]}\end{array}$ & $\begin{array}{c}\text { IS 808 } \\
{[1]}\end{array}$ & $\begin{array}{c}\text { GOST } \\
8239- \\
89[5]\end{array}$ & $\begin{array}{c}\text { GOST } \\
26020- \\
83[6]\end{array}$ & $\begin{array}{c}\text { GOST } \\
26020- \\
83[6]\end{array}$ & $\begin{array}{c}\text { GOST } \\
26020- \\
83[6]\end{array}$ \\
\hline Designation & LB400 & MB400 & WB400 & HB400 & 40 & $40 \mathrm{~B} 1$ & 40 SH1 & $40 \mathrm{~K} 1$ \\
\hline$h, \mathrm{~mm}$ & 400 & 400 & 400 & 400 & 400 & 392 & 388 & 393 \\
\hline$b, \mathrm{~mm}$ & 165 & 140 & 200 & 250 & 155 & 165 & 300 & 400 \\
\hline$t_{w}, \mathrm{~mm}$ & 8.0 & 8.9 & 8.6 & 9.1 & 8.3 & 7.0 & 9.5 & 11.0 \\
\hline$t_{f, \mathrm{~mm}}$ & 12.5 & 16.0 & 13.0 & 12.7 & 13.0 & 9.5 & 14.0 & 16.5 \\
\hline$I, \mathrm{~cm}^{4}$ & 19300 & 20500 & 23400 & 28100 & 19062 & 15750 & 34360 & 52400 \\
\hline$W, \mathrm{~cm}^{3}$ & 965 & 1025 & 1170 & 1405 & 953 & 804 & 1771 & 2664 \\
\hline$A, \mathrm{~cm}^{2}$ & 72.4 & 78.4 & 85.0 & 98.7 & 72.6 & 61.3 & 122.4 & 175.8 \\
\hline$M, \mathrm{~kg} / \mathrm{m}$ & 56.9 & 61.5 & 66.7 & 77.4 & 57.0 & 48.1 & 96.1 & 138.0 \\
\hline $\bar{W}$ & 1.59 & 1.50 & 1.52 & 1.45 & 1.57 & 1.71 & 1.32 & 1.15 \\
\hline $\bar{I}$ & 3.51 & 3.12 & 3.08 & 2.74 & 3.44 & 4.06 & 2.15 & 1.57 \\
\hline $\bar{i}$ & 1.87 & 1.77 & 1.75 & 1.65 & 1.86 & 2.02 & 1.47 & 1.25 \\
\hline
\end{tabular}

Comparing the specific characteristics for beam sections of these standards, it should be noted that they are practically the same for light cross sections (LB series according to the Indian standard and taper flange series according to the Ukrainian standard). For the cross sections designed for bending (MB series according to the Indian standard and B series according to the Ukrainian standard), the specific characteristics for the domestic sections are higher by an average of $15-40 \%$ when weight is $30-40 \%$ lower.

For heavy sections, which are also focused on the perception of longitudinal efforts, sections of the Indian product mix have higher specific characteristics and less weight by an average of $20-30 \%$. However, the value of the absolute geometric characteristics of the domestic product range is on average $1.5-1.8$ times higher, which in the design practice provides opportunities for their wider use.

Conclusions. On the basis of qualitative and quantitative comparison of the existing product mix of shaped hot rolled steel product mix of India and Ukraine the following conclusions should be made:

1. On the whole, the overall organization and principle of forming the product mix of the two countries are quite similar. The main fundamental difference is the availability in
India's standard of a wider range of section types within a single pitch, which allows you to more effectively choose the desired section in the design. However, the pitch itself is greater than in national standards, which negates this advantage.

2. Angle sections in India's standard have a wider range of thicknesses and larger number of section sizes, especially for unequal leg angles, due to the wide use of such sections in steel structural members.

3. Channel sections generally have approximately the same degree of efficiency and number of sizes in both countries. In the Indian standard, the taper flange sections are more widely represented, whereas in the domestic standard, the parallel flange sections prevail.

4. I-beam sections have the largest number of sizes in both product ranges, but unlike the domestic standard in the Indian standard, they are represented only by taper flange sections. In this case, the sections designed for bending, in domestic product mix, have specific characteristics on average $15-40 \%$ higher with $30-$ $40 \%$ lower weight. For sections of heavy series, designed to perceive longitudinal stress, sections of the product mix of India have higher specific characteristics and less weight by an average of $20-30 \%$. 


\section{REFERENCES}

1. IS (Indian Standard) 808. Dimensions for hot rolled steel beam, column, channel and angle sections, third rev. - New Delhi: BIS, 2002. P. 24. (in English)

2. DSTU (Building Standard) 2251-93 (GOST 8509-93). Steel hot rolled equal leg angels. Assortment. - Kyiv: State Standard of Ukraine, 1993. P. 17 (in Ukraine)

3. GOST (Building Standard) 8510-86*. Steel hot rolled unequal leg angels. Assortment. - Moscow: Standard Publishing, 1990. P. 5 (in Russian)

4. DSTU (Building Standard) 3436-96 (GOST 8240-97). Steel hot rolled channels. Assortment. - Kyiv: State Standard of Ukraine, 2004. P. 11 (in Ukraine)

5. GOST (Building Standard) 8239-89. Steel hot rolled beams. Assortment. - Moscow: Standard Publishing, 2001. P. 4 (in Russian)

6. GOST (Building Standard) 26020-83. Steel hot rolled beams with parallel edges of shelves. Assortment. - Moscow: Standard Publishing, 1984. P. 6 (in Russian)

7. IS (Indian Standard) 875-3. Code of practice for design loads (other than earthquake) for buildings and structures. Part 3 - Wind loads: second rev. - New Delhi: BIS, 2015. P. 69. (in English)

8. IS (Indian Standard) 1893-1. Criteria for earthquake resistant design of structures: fifth rev. New Delhi: BIS, 2002. P. 45. (in English)

9. IS (Indian Standard) 875-5. Code of practice for design loads (other than earthquake) for buildings and structures. Part 5 - Special loads and load combinations: second rev. - New Delhi: BIS, 1988. P. 26. (in English).

\section{Efficiency estimation of the shaped hot rolled steel product mix of India and Ukraine Gaidaichuk V.V., Bannikov D.O., Radkevich A.V., Muntian A.O.}

Summary. The publication presents main results of the performed quantitative and qualitative analysis of modern shaped rolled metal products of India, which is used for structural steel members. Its efficiency was compared to the current domestic product range of Ukraine on the example of angle bars, channel sections and flanged beams. Special attention is paid to the system of designations and marking of product mix items.

The publication presents the main results of the quantitative and qualitative analysis of the modern hot rolled steel assortment of India, which is used for steel building structures. The shaped hot rolled steel products are considered, represented in the standards of both countries by four types of profiles - equal leg angles, unequal leg angles, channel and beams. Special attention is paid to the system of designations and labeling of products of the assortment.

In general, it should be noted that the overall organization and principle of construction of the analyzed assortments of India and Ukraine are quite similar. The main fundamental difference is the availability in the standard of India of a wider range of profile varieties within one step, which makes it possible to more efficiently choose the required section in the design. However, the step itself is widely than in domestic standards, which negates such dignity.

Angels profiles in the Indian assortment have a wider range of thicknesses and are represented by a large number of sizes, especially for unequal leg angles, which is connected with a significant distribution of such profiles in the supporting elements of steel structures.

Channel profiles in general have approximately the same degree of efficiency and the number of standard sizes in the assortments of both countries. In the standard of India, profiles with flange slopped shelves are displayed in more way and, in the domestic standard, with parallel shelves.

Beam profiles have the largest number of sizes in both assortments, but unlike the domestic standard in India's standard, they are presented only in cross-sections with flange slopped shelves. In this case, the profiles aimed at bending, according to the domestic assortment have specific characteristics averaged on $15-40 \%$ higher with a less on $30-40 \%$ by weight. For profiles of heavy series, oriented also on the perception of longitudinal forces, sections in the Indian assortment have higher specific characteristics and less weight on average by $20-30 \%$.

Key words: product mix, metal rolling, steel constructions, metal structures, shaped sections, India, Ukraine. 